\title{
Hydrocephalus associated with occipital encephalocele: surgical management and clinical outcome
}

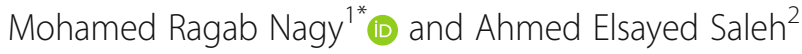

\begin{abstract}
Background: Encephaloceles are cystic congenital malformations in which central nervous system (CNS) structures, in communication with cerebrospinal fluid (CSF) pathways, herniate through a defect in the cranium. Hydrocephalus occurs in 60-90\% of patients with occipital encephaloceles.

Objective: Assessment of the surgical management of hydrocephalus associated with occipital encephalocele and its effect on the clinical outcome.

Methods: Between October 2015 and October 2019, a retrospective study was conducted on seventeen children with occipital encephaloceles who were operated upon. The presence of progressive hydrocephalus was determined by an abnormal increase in head circumference and an increase in the ventricular size on imaging studies. A ventriculoperitoneal (VP) shunt was applied in patients who had hydrocephalus. The clinical outcome was graded according to the developmental milestones of the children on outpatient follow-up visits.

Results: The mean age at surgery was 1.6 (range, 0-15) months. There were ten girls (58.8\%) and seven boys (41.2\%). Ten encephaloceles (58.8\%) contained neural tissue. Ten patients (58.8\%) had associated cranial anomalies. Eleven children (64.7\%) had associated hydrocephalus: four of them (36.4\%) diagnosed preoperatively, while seven children (63.6\%) developed hydrocephalus postoperatively. Ten of them (90.9\%) were managed by VP shunt. All children with hydrocephalus had some degree of developmental delay, including six (54.5\%) with mild/moderate delay and five (45.5\%) with severe delay. Half of the patients (50\%) of the children with occipital encephalocele without hydrocephalus had normal neurological outcome during the follow-up period ( $p$ value= 0.034 ).

Conclusions: Occipital encephalocele is often complicated by hydrocephalus. The presence of hydrocephalus resulted in a worse clinical outcome in children with occipital encephalocele, so it can help to guide prenatal and neonatal counseling.
\end{abstract}

Keywords: Encephalocele, Occipital, Hydrocephalus, Outcome

\section{Introduction}

An encephalocele is a congenital herniation of intracranial contents throughout a cranial defect. These intracranial contents, which protrude through the defect, may include cerebrospinal fluid (CSF), meninges, or/and brain tissue $[1,2]$. The estimated worldwide prevalence

\footnotetext{
* Correspondence: dr_mohamedragab@hotmail.com

${ }^{1}$ Faculty of Medicine, Cairo University, Giza, Egypt

Full list of author information is available at the end of the article
}

is $0.8-4$ per 10,000 live births $[3,4]$. Encephaloceles are generally classified based on the anatomical location where $75 \%$ of encephaloceles are located in the occipital region, $13-15 \%$ are situated in the frontal ethmoidal region, and $10-12 \%$ in the parietal or the sphenoidal region [5]. Infants with encephaloceles may often have associated malformations, reported to occur in 36-60\% of children [6] and include anomalies such as microcephaly, agenesis of the corpus callosum, 
holoprosencephaly, arachnoid cyst, Dandy-Walker malformation, Chiari malformation, craniosynostosis, cleft lip or palate, Klippel-Feil malformation, myelomeningocele, hydrosyringomyelia, and optic nerve abnormalities [5-8].

For a newborn with an encephalocele, the prognosis depends on many factors including the size and contents of the sac, presence of microcephaly, hydrocephalus, and associated anomalies [5, 8, 9]. A significant proportion of these children lack normal developmental milestones and may have mental and growth retardation, seizures, ataxia, and visual impairment [6]. Hydrocephalus carries a significant morbidity in these children, reported to occur in $60-90 \%$ of patients with occipital encephaloceles, with a much lower incidence of $10-15 \%$ in anterior encephaloceles $[10,11]$. Hydrocephalus is frequently present preoperatively or develops after the surgical repair of occipital encephaloceles. CSF diversion in the form of ventriculoperitoneal (VP) shunt is usually required in these cases [12].

The aim of this study was to assess the surgical management of hydrocephalus associated with occipital encephalocele and to correlate the clinical outcome with the presence of hydrocephalus in these pediatric patients.

\section{Methods}

In this study, a retrospective analysis of seventeen children with occipital encephaloceles who were operated upon in the Neurosurgery Department in Medina Maternity and Children Hospital in the interval between October 2015 and October 2019 was done. Newborns with anencephaly were excluded from the study.

Medical records of eligible children were reviewed regarding the age at presentation, sex, size, contents of encephalocele, presence of hydrocephalus, microcephaly, seizures, CSF leakage, associated cranial anomalies, and neurological outcome. Contents in the encephalocele were initially defined by imaging studies and then confirmed at the time of operation. Computed tomography (CT) and magnetic resonance imaging (MRI) of the brain were done in all cases. Ultrasonography was done in three children. The presence of progressive hydrocephalus was determined by an abnormal increase in head circumference, full fontanelle, and an increase in the ventricular size on imaging studies.

During surgery, the children with occipital encephaloceles were placed in the prone position. The sac was dissected from the surrounding normal skin. A microscope was used to magnify the visualization to aid decisionmaking in terms of whether to reposition or perform excision of neural tissue if present in the sac. This technique helped in preserving important structures associated with vital dural veins and vessels entangled within the mass. The dura mater was closed in a watertight fashion, a graft from pericranium was used when necessary, and fibrin glue was applied to strengthen the graft. The final step was closure of the subcutaneous tissue and the skin. In patients without neural tissue in the sac, only the dura mater was sealed. A ventriculoperitoneal shunt was applied in patients who had hydrocephalus. Two patients were operated by VP shunt insertion and encephalocele repair in the same setting. The sacs that ruptured before admission were managed by covering them with normal saline-soaked gauze in a sterile fashion and were taken to the operation theater for repair as soon as possible. The average amount of blood loss was $35 \mathrm{ml}$. Four patients required blood transfusion. Antiepileptic drugs were administered when the patient developed seizures.

Follow-up assessments were made on outpatient visits and included assessment of motor, visual, hearing, cognitive, and verbal developmental milestones. The visual function was assessed by an ophthalmologist by following a moving object, fundus examination, and visual evoked potential (VEP) when needed. The hearing was assessed by an audiologist by using otoacoustic emissions (OAE) test for screening and diagnostic auditory brainstem response (ABR) when indicated. According to the clinical outcome, children were divided into three groups. Children who reached all milestones appropriately were considered to have normal neurological status whereas children who did not meet all milestones were classified as having mild or moderate delay. Children were considered to have severe developmental delay if they were nonambulatory and nonverbal.

\section{Results}

A total of seventeen children, including ten girls (58.8\%) and seven boys (41.2\%), were included in this study. Their age ranged from 0 to 15 months, a mean age at surgery of 1.6 months.

The size of the encephalocele ranged from 1.5 to 15 $\mathrm{cm}$ in maximal diameter, with a mean of $4.5 \mathrm{~cm}$ (Fig. 1). Ten encephaloceles (58.8\%) contained neural tissue while in seven patients $(41.2 \%)$ the sac did not contain neural tissue. The protruded neural tissue was repositioned in six and it was partially excised and repositioned in four cases. Eleven children (64.7\%) had associated hydrocephalus: four of them (36.4\%) diagnosed preoperatively, while seven children $(63.6 \%)$ developed hydrocephalus postoperatively (Fig. 2). The average duration between surgery and development of hydrocephalus in the 7 patients with postoperative hydrocephalus was 1.5 (range, 1-5) weeks. Two infants (11.8\%) presented with CSF leaking from the encephalocele, with one being infected. Ten patients $(58.8 \%)$ had associated cranial anomalies where six children had cranial 


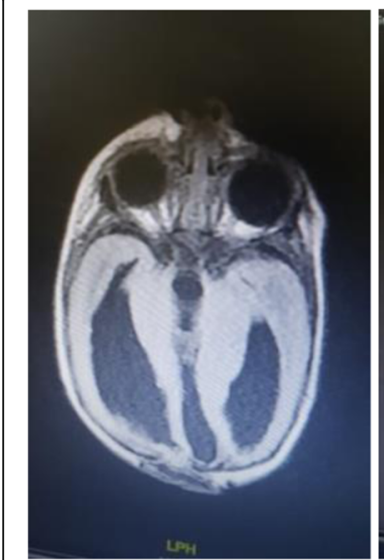

a

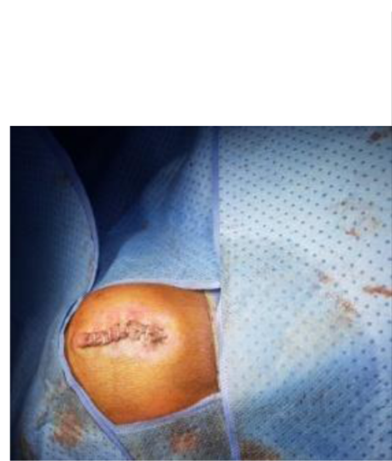

e

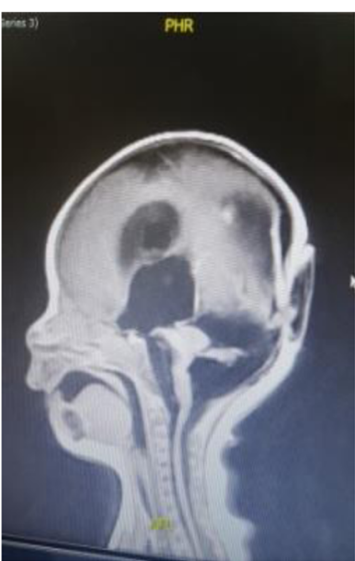

b

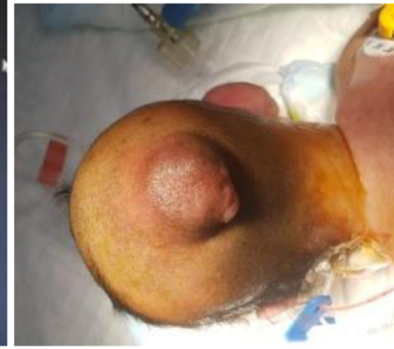

c

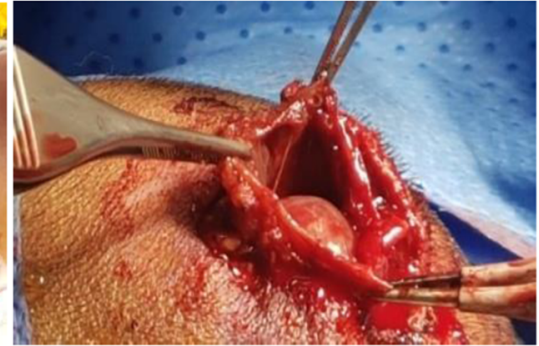

d

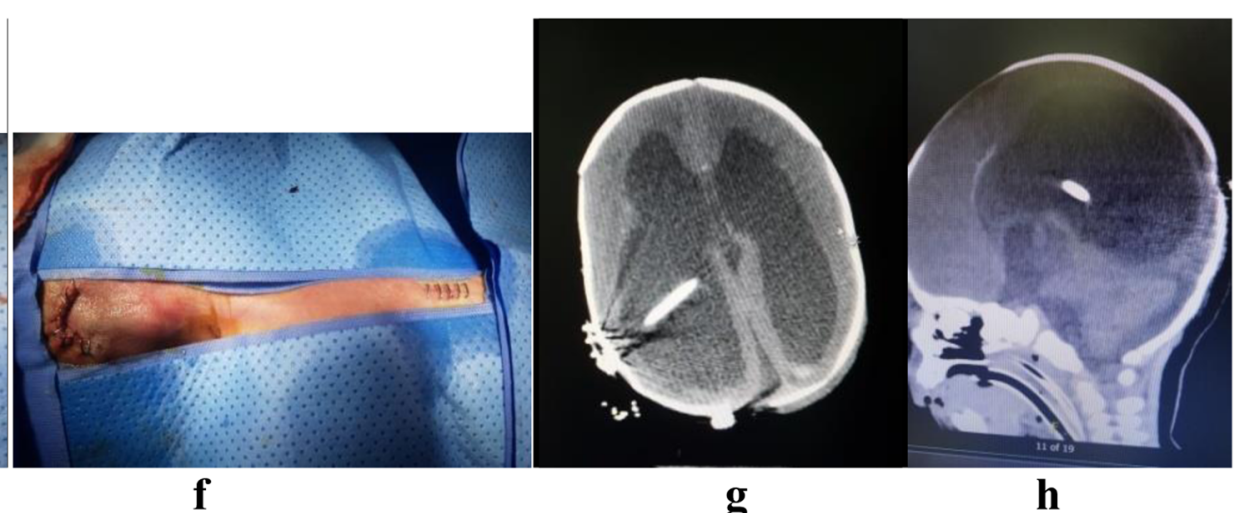

Fig. 1 A 10-day boy. a, b Axial and sagittal T1-weighted MRI brain showing occipital encephalocele with communicating hydrocephalus and Dandy-Walker malformation. $\mathbf{c}, \mathbf{d}$ Intraoperative pictures showing that the encephalocele contained gliosed brain tissue. e, $\mathbf{f}$ Intraoperative pictures after repair of encephalocele and insertion of VP shunt. $\mathbf{g}, \mathbf{h}$ Postoperative axial and sagittal CT brain showing the repaired encephalocele with the inserted VP shunt

anomalies alone and four children had a combination of both cranial and extracranial anomalies. Seven children (41.2\%) had no associated cranial anomalies. The commonly associated cranial abnormalities included microcephaly (Fig. 3), Dandy-Walker malformation, and agenesis of the corpus callosum while the most commonly associated extracranial anomaly was cleft lip/palate (Table 1). The three patients with Dandy-Walker malformation were managed by VP shunt.

All patients underwent surgical excision and repair of the encephalocele. Of the two neonates with CSF leaking from the encephalocele at birth, one was infected and was managed with appropriate broad-spectrum antibiotics and a temporary CSF drainage. VP shunt was required later on after clearance of infection. The other one developed progressive hydrocephalus and required CSF diversion. VP shunt was inserted in ten (90.9\%) out of the eleven patients with hydrocephalus. One patient (9.1\%) did not develop progressive hydrocephalus and thus did not require CSF diversion during 9 months of the follow-up period. Two shunt revisions were performed 1.5 and 2 years after shunt insertion. Two children $(11.8 \%)$ developed a seizure disorder following the repair where they had good control with one antiepileptic drug. The overall survival rate was 94.1\% (16/17). The child who died presented with occipital encephaloceles larger than $5 \mathrm{~cm}$ and died of causes unrelated to repair of the encephalocele or a shunting procedure. The cause of death was associated extracranial anomalies and poor general condition.

The follow-up period ranged between 6 months and 4.5 years with the mean follow-up of 2 years. As regards the clinical outcome, three children (17.6\%) were neurologically normal, eight patients (47.1\%) had mild/moderate delay, and six (35.3\%) had severe developmental delay. None of the patients with hydrocephalus had a normal neurological outcome; all eleven children had some degree of developmental delay, including six 


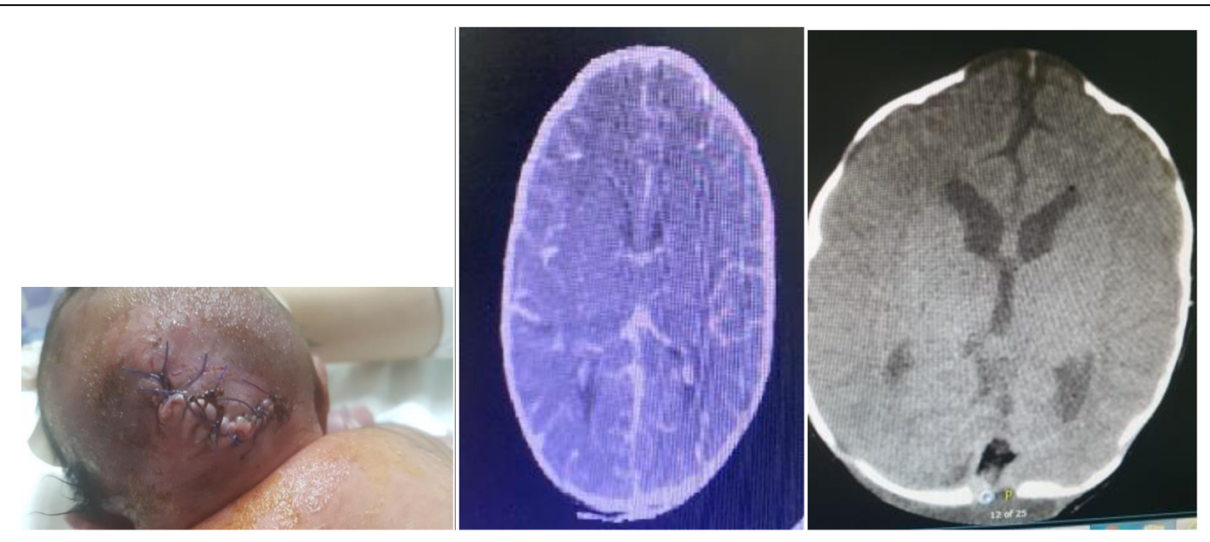

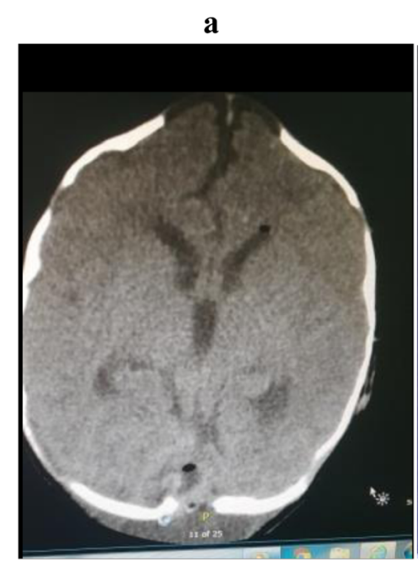

d b

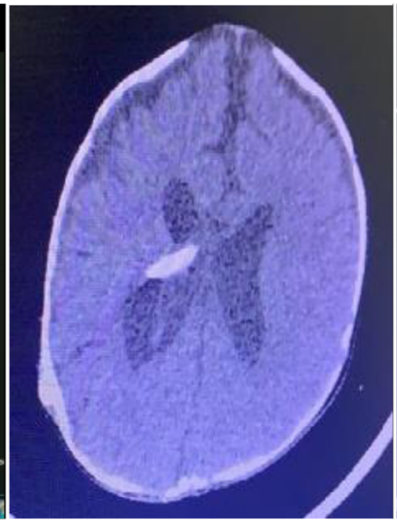

e

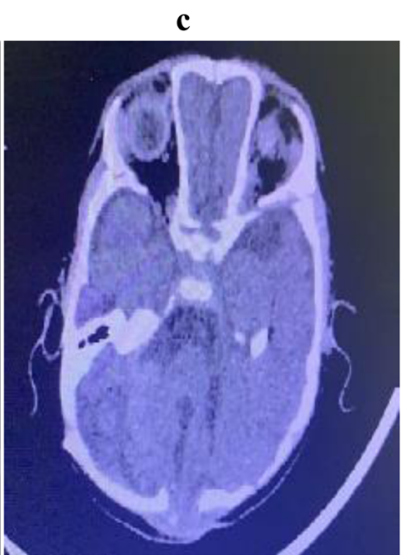

f

Fig. 2 A boy who was operated for occipital encephalocele when he was 7 days old. a He developed a CSF collection at the surgical site 1 week following the surgery. $\mathbf{b}$ Preoperative axial $C T$ brain. $\mathbf{c}$, $\mathbf{d}$ Postoperative axial $C T$ brain showing that he developed dilation of the supratentorial ventricles and CSF collection at the surgical site. e, f Axial CT brain after VP shunt insertion showing reduction of the CSF collection size. The child improved and discharged 3 days later

(54.5\%) with mild/moderate delay and five (45.5\%) with severe delay. Half of the patients $(50 \%)$ of the children with occipital encephalocele without hydrocephalus had normal neurological outcome during the follow-up period $(p$ value $=0.034)($ Table 2$)$.

\section{Discussion}

Encephaloceles most probably occur as a result of mesodermal abnormality that causes a defect in the calvarium and dura through which protrudes the brain tissue. This usually occurs at 8-12 weeks of gestation [13]. The associated risk factors remain obscure. Risk factors include hyperthermia, genetic background, maternal nutritional deficiency, aflatoxin, or other environmental factors [14]. Children with occipital encephaloceles had a higher rate of progressive hydrocephalus and developmental delay than those with anterior lesions [3].

Females were affected predominantly $(10 / 17,58.8 \%)$ in this study which correlates with previous reports [14].
The mean age of the children was 1.6 (range, 0-15) months. The size of the encephalocele sac ranged from 1.5 to $15 \mathrm{~cm}$, with a mean of $4.5 \mathrm{~cm}$ in maximal diameter. Ten encephaloceles (58.8\%) contained neural tissue. Kiymaz et al. reported 30 children with occipital encephaloceles ( 22 girls and 8 boys), whose ages varied between newborn and 14 months. The encephalocele sac was located in the occipital region in 27 patients (90\%) and in the occipitocervical region in 3 patients (3\%). The range of size measurements of 21 sacs was from $1 \times 1$ $\mathrm{cm}$ to $20 \times 20 \mathrm{~cm}$. Neural tissue was present in 16 of the patients, while it was absent in 14 patients [9].

The contents of the sac varied from dysplastic diverticulum to brain tissue with some amount of CSF always present. The skull defects are frequently small. Larger occipital encephaloceles herniating through smaller bony defects require urgent surgical intervention to avoid damage to the functioning brain tissues and intracranial vessels that go in and out of the sac to supply the brain 


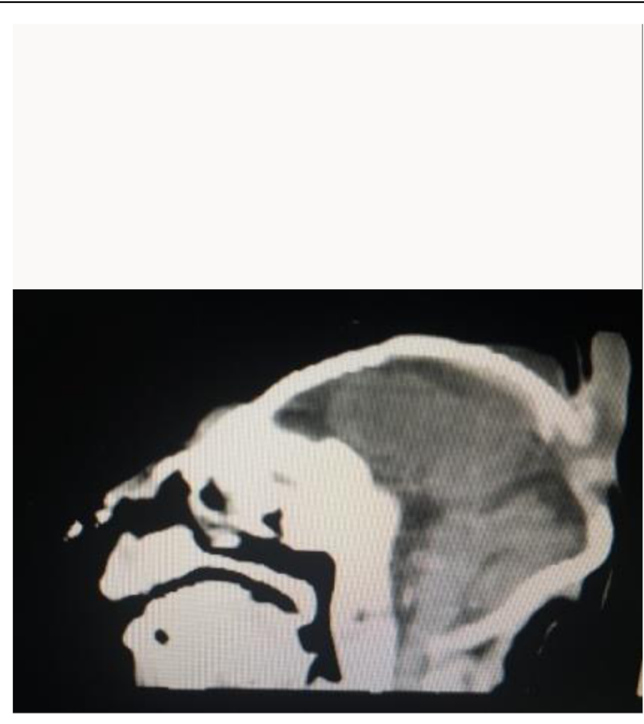

$\mathbf{a}$

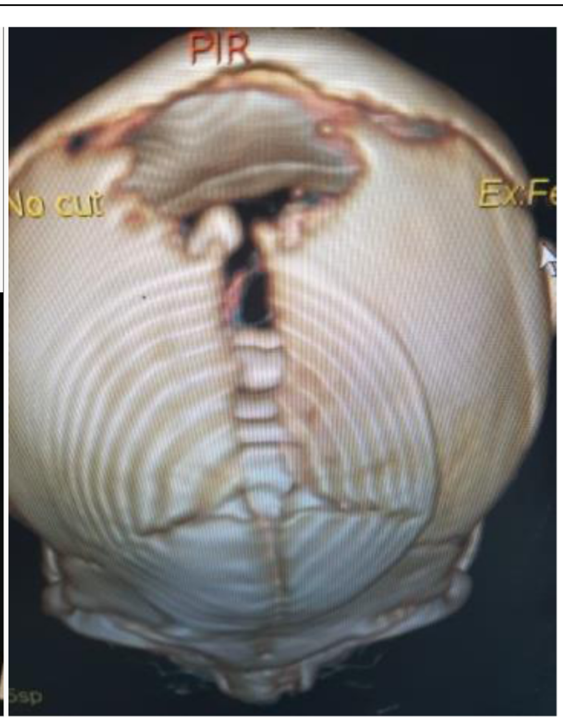

b

Fig. 3 A female infant with microcephaly. a Sagittal CT brain with IV contrast showing occipital encephalocele with abnormal shape small size skull, the corpus callosum cannot be detected. b 3D bone window reconstruction shows a posterior parieto-occipital midline bony defect about 1.7-cm diameter through which the encephalocele protrudes. The patient was operated for repair of the encephalocele

tissue. Excision of the protruded neural tissue should be performed without affecting the vessels, especially veins and sinuses; otherwise, massive brain infarction may occur [15]. Microscopic surgery can achieve these goals more efficiently. In this series of patients, there was no infarction postoperatively after the repair.

Prenatal ultrasonography can be used to detect an encephalocele and the presence or absence of brain tissue within the sac [5]. Hydrocephalus is often not present prenatally. Hydrocephalus may develop due to torsion of the aqueduct of the Sylvius, sinus, or aqueduct stenosis. Hydrocephalus may also occur after elimination of the encephalocele because of changes in the CSF circulation dynamics or obstruction of the sagittal sinus which may occur during closure of the encephalocele. Various patient series show that hydrocephalus is associated with large posterior encephaloceles $[10,11]$,

Table 1 Associated cranial and extracranial anomalies

\begin{tabular}{ll}
\hline Anomaly & Number \\
\hline Cranial & 10 \\
Microcephaly & 3 \\
Dandy-Walker malformation & 3 \\
Agenesis of the corpus callosum & 2 \\
Chiari malformation & 2 \\
Extracranial & 4 \\
Cleft lip/palate & 3 \\
Facial dysmorphism & 1 \\
\hline
\end{tabular}

although it is more likely to develop following repair of the lesion than be present at birth. In our study, hydrocephalus was observed preoperatively in four patients (36.4\%) who were treated by placing VP shunt before the repair of the sac. Meanwhile, seven children (63.6\%) developed hydrocephalus after surgery; six of them were again successfully managed by VP shunt as second surgery.

There is always a chance of infection in large encephalocele usually because there is a leakage of CSF [16]. In this study, one neonate presented with infected CSF leaking from the encephalocele and he was managed with proper antibiotics and regular sterile dressings and a temporary CSF drainage. VP shunt was required later on after clearance of infection. All surgeries were elective except two patients that were admitted with rupture of the sac and CSF leakage which were repaired on emergency basis. Infections could increase the rates of morbidity and mortality in these patients.

In this study, eleven children (64.7\%) had hydrocephalus where ten of them (90.9\%) were managed by VP shunt. We did not apply endoscopic third ventriculostomy (ETV) in any child in this study due to the known poor results of ETV in this age group due to underdeveloped subarachnoid space. However, in one study, it was concluded that ETV can be an effective treatment option for encephalocele-associated hydrocephalus, even in children under the age of 1 year and it may obviate the need for placement of CSF shunts that have a risk of infection and malfunction. However, they reported that 
Table 2 The neurological outcome in relation to the presence of hydrocephalus

\begin{tabular}{llllll}
\hline No. & Inclusion criteria & No. of & \multicolumn{2}{l}{ Neurological outcome } \\
\cline { 5 - 6 } & & patients & Normal & Mild or moderate delay & Severe developmental delay \\
\hline $\mathbf{1}$ & Children with hydrocephalus & 11 & $0(0 \%)$ & $6(54.5 \%)$ & $5(45.5 \%)$ \\
$\mathbf{2}$ & Children without hydrocephalus & 6 & $3(50 \%)$ & $2(33.3 \%)$ & $1(16.7 \%)$ \\
Total & & 17 & $3(17.6 \%)$ & $8(47.1 \%)$ & $6(35.3 \%)$ \\
\hline
\end{tabular}

delayed failure of ETV may occur as seen in their first patient, indicating the need for careful and long-term follow-up [17].

In our study, $35.3 \%$ of children had severe developmental delay and $47.1 \%$ had mild or moderate delay while $17.6 \%$ had a normal neurological outcome. This result is higher than other reports which found that 16$31 \%$ of the children were physically and/or mentally disabled such as those reported by Tsuchida et al. [18], Docherty et al. [19], Date et al. [20], Macfarlane et al. [21], and Martínez-Lage et al. [22]. This is maybe due to many of encephaloceles in our study contained neural tissue $(10,58.8 \%)$, most of the children had hydrocephalus $(11,64.7 \%)$, and many infants had associated intracranial and extracranial anomalies (10, 58.8\%). Among the hydrocephalic patients in this study, none had a normal neurological outcome. This is in agreement with previous reports that found that hydrocephalus is significantly associated with cognitive deficit in children with encephaloceles [3, 20, 23]. Da Silva et al. reported seventy children with encephalocele (14 anterior and 56 posterior encephaloceles). Their outcome showed that 14 patients $(20 \%)$ had severe developmental delay, 28 (40\%) had mild/moderate delay, and 28 (40\%) were neurologically normal. In their series, none of the patients with hydrocephalus had a normal neurological outcome; all 17 children had some degree of developmental delay, including 11 (65\%) with mild/moderate delay and 6 (35\%) with severe delay [24].

Microcephaly is a poor prognostic factor which is associated with developmental delays. It sometimes makes the relocation of herniated neural tissue more difficult, with a subsequent increase in intracranial pressure [9]. Gallo described a technique where an extracranial compartment is prepared utilizing fine tantalum mesh to enclose the neural contents. This mesh is attached to the periphery of the skull defect providing a rigid extracranial compartment for the encephalocele. As intracranial pressure increases, the calvarium is forced to expand [25]. We did not face this problem in our series as all the gliotic brain tissue which was protruding out of the skull was excised when needed with the aid of preoperative imaging that was carried out to identify this type of tissue and to detect any involved blood vessels. This is similar to the findings of other series [9]. Three of our patients had associated Dandy-Walker cysts along with hydrocephalus. Hydrocephalus should not be treated before treatment of Dandy-Walker cyst due to the risk of upward herniation of posterior fossa contents. Hydrocephalus and Dandy-Walker cyst are usually treated in the same setting by a single shunt system connected through $\mathrm{Y}$ connector. Other options include posterior fossa cyst drainage alone or ventricular drainage alone [26].

A seizure is an important factor to affect the quality of life in children with occipital encephalocele [3]. Bui et al. reported an incidence of seizures in occipital encephalocele of $17 \%$ [27]. In our study, the seizure was noted in two children $(11.8 \%)$ who developed it following the repair which is slightly less than other reported studies [3, 19]. Seizures in these patients were well-controlled with antiepileptics after surgery. Mortality was $5.9 \%$ in this study which correlates to recent reports [24].

The limitations of this study include that it is a retrospective one with no limitation during patient selection by the volume of viable neural tissue. Prospective studies with more concern about the volume of viable neural tissue and the quality of the life of the patients following surgery for occipital encephaloceles with hydrocephalus are recommended to authenticate the results.

\section{Conclusion}

Occipital encephalocele is often complicated by hydrocephalus. Management of hydrocephalus is crucial in preventing dehiscence at the site of the encephalocele repair. In contrast to good or fair neurological outcome in children with an encephalocele without hydrocephalus, the presence of hydrocephalus resulted in a worse neurological outcome. This can help to guide prenatal or neonatal counseling.

\section{Abbreviations}

ABR: Auditory brainstem response; CNS: Central nervous system; CSF: Cerebrospinal fluid; CT: Computed tomography; ETV: Endoscopic third ventriculostomy; MRI: Magnetic resonance imaging; OAE: Otoacoustic emissions; VEP: Visual evoked potential; VP shunt: Ventriculoperitoneal shunt

\section{Acknowledgements}

The authors acknowledge all staff members of the Neurosurgery Department in Medina Maternity and Children Hospital for their support and help during this work. 


\section{Authors' contributions}

Both authors participated evenly in this research, and both operated the cases and participated in the data analysis and writing of the manuscript. The author MRN participated in the data collection and analysis, did the literature review, and wrote the manuscript. The author AES initiated the idea of this research, designed the research, participated in the data collection and analysis, and revised the final manuscript. All authors have read and approved the final manuscript.

\section{Funding}

The authors received no financial support for the research, authorship, and/ or publication of this article.

\section{Availability of data and materials}

The datasets used and/or analyzed during the current study are available from the corresponding author on reasonable request.

\section{Declarations}

\section{Ethics approval and consent to participate}

We had approval from the local ethical committee concerning aspects of medical research. All fathers of children included in this study had signed consent to participate in this research and to publish the data before being included in the study. The ethical committee of the Neurosurgery Department, Medina Maternity and Children Hospital, approved this research prior to starting it, June 2015.

\section{Consent for publication}

All fathers of children included in this study had signed consent to participate in this research and to publish the data before being included in the study.

\section{Competing interests}

The authors declare that they have no competing interests.

\section{Author details}

${ }^{1}$ Faculty of Medicine, Cairo University, Giza, Egypt. 'Faculty of Medicine, Benha University, Benha, Egypt.

\section{Received: 19 April 2020 Accepted: 15 April 2021}

Published online: 01 June 2021

\section{References}

1. Barone C, Jimenez D, Helling E, Laskey A. What is the incidence of hypertelorism in Filipino frontonasal encephalocele patients? J Craniofac Surg. 2007;18(2):268-73. https://doi.org/10.1097/01.scs.0000246501.92559.da.

2. Bozinov O, Tirakotai W, Sure U, Bertalanffy $H$. Surgical closure and reconstruction of a large occipital encephalocele without parenchymal excision. Childs Nerv Syst. 2005;21(2):144-7. https://doi.org/10.1007/s00381004-1020-5.

3. Lo BW, Kulkarni AV, Rutka JT, Jea A, Drake JM, Lamberti-Pasculli M, et al. Clinical predictors of developmental outcome in patients with cephaloceles. J Neurosurg Pediatr. 2008;2(4):254-7. https://doi.org/10.31 71/PED.2008.2.10.254.

4. Siffel C, Wong LY, Olney RS, Correa A. Survival of infants diagnosed with encephalocele in Atlanta, 1979-98. Paediatr Perinat Epidemiol. 2003;17(1): 40-8. https://doi.org/10.1046/j.1365-3016.2003.00471.x.

5. Raja R, Qureshi A, Memon A, Ali H, Dev V. Pattern of encephaloceles: a case series. J Ayub Med Coll Abbottabad. 2008;20:125-8.

6. Mahajan C, Rath GP, Dash HH, Bithal PK. Perioperative management of children with encephalocele: an institutional experience. J Neurosurg Anesthesiol. 2011;23(4):352-6. https://doi.org/10.1097/ANA.0b013e31821 f93dc.

7. Kotil K, Kilinc B, Bilge T. Diagnosis and management of large occipitocervical cephaloceles: a 10-year experience. Pediatr Neurosurg. 2008;44(3):193-8. https://doi.org/10.1159/000120149.

8. Upadhyaya V, Upadhyaya DN, Sarkar S. Sincipital encephalocele with corpus callosum agenesis and intracranial lipoma: a case report. Indian J Radiol Imaging. 2005;15(4):507-10. https://doi.org/10.4103/0971-3026.28784.
9. Kiymaz N, Yilmaz N, Demir I, Keskin S. Prognostic factors in patients with occipital encephalocele. Pediatr Neurosurg. 2010;46(1):6-11. https://doi. org/10.1159/000314051.

10. Alexiou GA, Sfakianos G, Prodromou N. Diagnosis and management of cephaloceles. J Craniofac Surg. 2010;21(5):1581-2. https://doi.org/10.1097/ scS.0b013e3181edc3f6.

11. Mahapatra AK. Anterior encephalocele - AlIMS experience a series of 133 patients. J Pediatr Neurosci. 2011;6(Suppl 1):S27-30. https://doi.org/10.41 03/1817-1745.85706

12. Kanesen D, Rosman AK, Kandasamy R. Giant occipital encephalocele with Chiari malformation type 3. J Neurosci Rural Pract. 2018;9(4):619-21. https:// doi.org/10.4103/jnrp.jnrp_103_18.

13. McComb JG, Encephaloceles, in Youmans JR. Neurological surgery: a comprehensive reference guide to the diagnosis and management of neurosurgical problems, ed 4. Philadelphia: WB Saunders; 1996. p. 829-42.

14. Wen S, Ethen M, Langlois PH, Mitchell LE. Prevalence of encephalocele in Texas, 1999-2002. Am J Med Genet A. 2007;143A(18):2150-5. https://doi. org/10.1002/ajmg.a.31907.

15. Walia B, Bhargava BP, Shandu K. Giant occipital encephalocele. Med J Armed Forces India. 2005;61(3):293-4. https://doi.org/10.1016/S0377-123 7(05)80181-9.

16. Aslan A, Eser $O$, Doğru $O$, Aktepe $F$, Yurumez Y, Fidan H. Occipital mega encephalocele associated with acute inflammation. Pediatr Neurosurg. 2007; 43(1):65-6. https://doi.org/10.1159/000097530.

17. Moorthy RK, Rajshekhar V. Management of hydrocephalus associated with occipital encephalocoele using endoscopic third ventriculostomy: report of two cases. Surg Neurol. 2002;57(5):351-5; discussion 355. https://doi.org/10.1 016/S0090-3019(02)00696-1.

18. Tsuchida T, Okada K, Ueki K. The prognosis of encephaloceles (author's transl). No Shinkei Geka. 1981;9:143-50 Jpn.

19. Docherty JG, Daly JC, Carachi R. Encephaloceles: a review 1971-1990. Eur J Pediatr Surg. 1991;1(Suppl 1):11-3.

20. Date I, Yagyu Y, Asari S, Ohmoto T. Long-term outcome in surgically treated encephalocele. Surg Neurol. 1993;40(2):125-30. https://doi.org/10.1016/ 0090-3019(93)90122-H

21. Macfarlane R, Rutka JT, Armstrong D, Phillips J, Posnick J, Forte V, et al. Encephaloceles of the anterior cranial fossa. Pediatr Neurosurg. 1995:23(3): 148-58. https://doi.org/10.1159/000120952.

22. Martínez-Lage JF, Poza M, Sola J, Soler CL, Montalvo CG, Domingo R, et al. The child with a cephalocele: etiology, neuroimaging, and outcome. Childs Nerv Syst. 1996;12(9):540-50. https://doi.org/10.1007/BF00261608.

23. Czech T, Reinprecht A, Matula C, Svoboda H, Vorkapic P. Cephaloceles experience with 42 patients. Acta Neurochir (Wien). 1995;134(3-4):125-9. https://doi.org/10.1007/BF01417678.

24. Da Silva SL, Jeelani Y, Dang H, Krieger MD, McComb JG. Risk factors for hydrocephalus and neurological deficit in children born with an encephalocele. J Neurosurg Pediatr. 2015;15(4):392-8. https://doi.org/10.31 71/2014.10.PEDS14192.

25. Gallo AE. Repair of giant occipital encephaloceles with microcephaly secondary to massive brain herniation. Childs Nerv Syst. 1992:8(4):229-30. https://doi.org/10.1007/BF00262854

26. Alexiou GA, Sfakianos G, Prodromou N. Dandy-Walker malformation: analysis of 19 cases. J Child Neurol. 2010;25(2):188-91. https://doi.org/10.1177/0883 073809338410.

27. Bui CJ, Tubbs RS, Shannon CN, Acakpo-Satchivi L, Wellons JC, Blount JP, et al. Institutional experience with cranial vault encephalocele. J Neurosurg Pediatr. 2008:1:22-5.

\section{Publisher's Note}

Springer Nature remains neutral with regard to jurisdictional claims in published maps and institutional affiliations. 